\title{
Longevity and mortality of captive chimpanzees in Japan from 1921 to 2018
}

\section{AUTHOR(S):}

Havercamp, Kristin; Watanuki, Koshiro; Tomonaga, Masaki; Matsuzawa, Tetsuro; Hirata, Satoshi

\section{CITATION:}

Havercamp, Kristin ...[et al]. Longevity and mortality of captive

chimpanzees in Japan from 1921 to 2018. Primates 2019, 60(6): 525-535

\section{ISSUE DATE:}

2019-11

URL:

http://hdl.handle.net/2433/264625

\section{RIGHT:}

This is a post-peer-review, pre-copyedit version of an article published in Primates. The final authenticated version is available online at: https://doi.org/10.1007/s10329-017-0648-1.; The full-text file will be made open to the public on 3 October 2020 in accordance with publisher's 'Terms and Conditions for Self-Archiving'; This is not the published version. Please cite only the published version. この論文は出版社版でありません。引用の際には出版社版をご確認ご 利用ください。 
Title:Longevity and mortality of captive chimpanzees in Japan from 1921 to 2018

\title{
Authors:
}

Kristin Havercamp ${ }^{1}$, Koshiro Watanuki ${ }^{2}$, Masaki Tomonaga ${ }^{2}$, Tetsuro Matsuzawa ${ }^{2,3,4}$, Satoshi Hirata ${ }^{1}$

\author{
Affiliations: \\ 606-3201, Japan \\ ${ }^{2}$ Primate Research Institute, Kyoto University, Inuyama, Japan \\ ${ }^{3}$ Institute for Advanced Study, Kyoto University, Kyoto, Japan \\ ${ }^{4}$ Japan Monkey Centre, Inuyama, Japan
}

${ }^{1}$ Wildlife Research Center, Kyoto University, 2-24 TanakaSekiden-cho, Sakyo, Kyoto

\begin{abstract}
Utilizing the Great Ape Information Network (GAIN), an open-access nationwide database containing the detailed life history information of all apes who have lived or currently reside in Japan, we present a robust chimpanzee life table by single year of age and sex including 821 individuals spanning nearly a century, current through March 11, 2019. While the demographic composition and status of captive chimpanzees in Japan has been previously reported, longevity and mortality statistics have not. We show that female and male survivorship do not differ significantly, and that a live-born chimpanzee in Japan can expect to live 28.3 years (females 26.3, males 30.3). Life expectancy increases to 34.6 years (females 33.4, males 35.7) for individuals who reach one year of age, and to 40.4 years (females 39.2, males 41.5) for those who survive to adulthood. The oldest chimpanzee in Japan, a wild-born male, lived an estimated 68 years. One in six infants are stillborn, and nearly $80 \%$ of all infants born alive survive beyond their first birthday. Finally, we report that a seasonal death pattern exists and chimpanzees in Japan are more likely to decease in the winter months (Dec-Feb) than in any other season.
\end{abstract}

Keywords Captive chimpanzee, Life table, Life history patterns, Longevity, Mortality 


\section{Introduction}

Due to humans' closely shared evolutionary history with chimpanzees (Pan troglodytes), their longevity, mortality, and reproductive patterns have been studied to better understand human life history evolution (e.g., Hill et al. 2001; Thompson et al. 2007; Muller and Wrangham 2014; Wood et al. 2017). Mortality data from five wild chimpanzee study sites including Gombe, Taï, Kibale, Mahale, and Bossou indicate that life expectancy for both sexes at birth is less than 15 years. Individuals reaching age 15 survive around 15 years longer, leading to a life expectancy of around 30, with males experiencing higher adult mortality than females (Hill et al. 2001). The maximum longevity of a wild chimpanzee reported in 2017 is an estimated 66 years at Ngogo in Uganda (Wood et al. 2017). Compared to human hunter-gatherers, wild chimpanzees experience around half the life expectancy at birth and less than half post-adulthood (calculated from age 15), and their mortality rate is seven times higher between 30 and 35 years of age than that of the Ache (Kaplan et al. 2000; Hill et al. 2001). However, chimpanzees living in Ngogo, an environment with high fruit availability, have an average life expectancy at birth more comparable to that of hunter-gatherers, of 32.8 years (Wood et al. 2017).

Life history statistics are easier to obtain for captive chimpanzees compared to their wild counterparts, yet robust data are missing in the literature. The first life table for captive chimpanzees was published nearly 30 years ago and included 87 individuals (Courtenay and Santow 1989). The authors were only able to calculate mortality probabilities up to age 30 due to the young population at that time. Since Courtenay and Santow (1989), two additional captive chimpanzee life tables have been published in scientific journals, and both are now relatively outdated (Dyke et al. 1995; Littleton 2005). Calculations from observed data valid through 1995 reported that females could expect to live 23.1 years, whereas a fitted model estimated 44.9 years (Dyke et al. 1995). Other studies have gathered life table data from databases such as Species360 to investigate animal longevity, however the chimpanzee cohort data analyzed were also missing recent data (Tidière et al. 2016). Thirteen years have passed since original data on captive chimpanzee mortality or longevity have been published or updated, not including studbooks which are more commonly shared privately amongst zoo communities, and existing life tables are relatively small for demographic analyses. The accuracy of life history calculations depends on the length of time a population has been maintained and tracked, and thus a more current and robust life table is necessary to improve our understanding of captive chimpanzee demographic life history patterns. 
Animals living in captivity may experience different mortality rates, as well as reproductive patterns, from those living in the wild under more natural conditions. Whether or not captive chimpanzees outlive their wild counterparts is unclear. While in some settings wild adult chimpanzees experience higher overall mortality risk than captive living individuals (Courtenay and Santow 1989; Hill et al. 2001), in others captive males and females live 6 and 7 years less, respectively, however the number of individuals included in this study were few (Tidière et al. 2016). Extended survival in captivity has been explained by the high level of care animals receive (e.g., high quality and various nutritional food items, health care) and lack of predators, however individuals may also experience negative effects such as human-induced illnesses, a lack of exercise, over feeding (which could lead to health issues such as diabetes or heart disease) and increased intraspecific violence due to living in a confined space (Hill et al. 2001; Kohler et al. 2006). Also, captive conditions may vary across facilities (e.g., zoos, sanctuaries, research institutes), which might influence life history parameters, something which has been so far difficult to explore.

The goal of our current study was to utilize the 97 years of data included in the Great Ape Information Network (GAIN) database to examine the demographic life history patterns of captive chimpanzees in Japan. Initiated in 2002 by Tetsuro Matsuzawa and colleagues, GAIN was developed to counteract the shortage of captive primate data with the goal to provide accessible and real-time data on all nonhuman apes (henceforth apes), great and small, previously or currently living throughout Japan (Matsuzawa 2016b). The three main aims of GAIN include (1) the promotion of non-invasive scientific research through a real-time utilization system of bio-resource samples, such as a dead body, (2) assistance in primate population management, and (3) promotion of animal welfare and facilitation of networks between zoo staff and researchers. Historical data on apes in GAIN date back to 1921, when the first chimpanzee arrived to Japan (Watanuki et al. 2014). Current to March 11, 2019, the highest number of individual data recorded in the GAIN database is 1017 chimpanzees, followed by 589 gibbons, 255 orangutans, 122 gorillas, and six bonobos. At the time of writing, 307 chimpanzees, 176 gibbons, 46 orangutans, 21 gorillas, and six bonobos reside in Japan.

Using the database, we produced a robust life table to better understand demographic life history patterns including age-specific mortality rates and calculated the life expectancy and maximum longevity of captive chimpanzees; this is the first such report using 
available data on chimpanzees in Japan. We also investigated whether patterns in death seasonality exist, which to our knowledge has never been determined for a captive chimpanzee population, and attempted to answer whether or not life expectancy in captivity has increased over time. Finally, we discussed the existing literature on both wild and captive chimpanzees to examine how life history patterns differ across environments and populations, especially in comparison to the captive population in Japan.

\section{Methods}

\section{Data}

We obtained records on every chimpanzee who has previously lived or currently lives in Japan from the open-access GAIN database (https://shigen.nig.ac.jp/gain/). The majority of individuals have a detailed record of their entire lifespan available to users including information such as date of birth and death, sex, birth place, current location, any dates and locations of transfer, reproductive history, family pedigree, early life experiences, and a brief physical and personality description. Current to March 11, 2019, information on 1017 chimpanzees existed, more than any other species in the database. At the time of writing, 307 were living in 49 different facilities including zoos, research institutions and sanctuaries. There is only one sanctuary in Japan, Kumamoto Sanctuary, however this facility was owned by a biomedical research company until it was taken over by Kyoto University in 2011 (Morimura et al. 2011); a total of 193 chimpanzees have spent either all or some part of their life there (Fig. 1). More than 76 additional individuals were housed across eight biomedical research institutions at some point during their lives, at least 26 in two research institutes, and the remaining majority in a zoo, park, or center. Although likely an underestimation, 33 individuals have been documented as privately owned and an additional 24 as unknown. This history of this population has been described in more detail by Watanuki et al. (2014), Ochiai et al. (2015), and in English by Hirata et al. (in press). These data were entered into PopLink 2.4 (release date Dec 15, 2012; https://www.lpzoo.org/conservation-science/projects/ poplink), a captive population management software (Faust et al. 2012a). PopLink data were imported into PMx (http:// www.vortex10.org/PMx.aspx) for the production of the current age-sex composition chart (Ballou et al. 2010).

\section{Age estimation}

Only following 1926 were definite birth dates recorded for individuals born in captivity. The recorded year of birth of all chimpanzees who were born in the wild or have an 
unknown origin is an estimate. In the majority of cases, individuals were allocated an estimated year of birth based on morphological features and age-typical behaviors at the time of importation. Underestimation of age may have occurred more frequently in earlier years of importation due to the lack of detailed knowledge about chimpanzee development. Of all individuals in the database, 394 (39\%) did not have a definite year of birth on record. Individuals recorded as having an estimated year of birth or death were allocated a birth or death day of July 1st following instructions set by the developers of PopLink to use the middle date of the estimated year (Faust et al. 2012b). The date estimate for such cases was entered as "Year" within the software, which allows for the acknowledgement of less precise dates however uses the specified mean transaction date to calculate age-specific demographic parameters. Individuals with no known or estimated date of birth, capture, departure, or death were not included in analyses.

\section{Lost to follow-up (LTF)}

In total, 173 chimpanzees documented by GAIN were lost to follow-up (LTF) cases, 125 of which were exported out of Japan to another institution. The remaining 48 remained in Japan but were no longer tracked. The first documented exportation was in 1931 when a privately owned, American-born individual was believed to be brought back to America. The most recent exportations were in September of 2015, when three chimpanzees were moved to Malaysia. Other LTF cases included known deceased individuals without any recorded year of death estimate. Individuals with available birth and LTF data were included in the life table, but censored at the age of departure; rather than assumed death, they simply disappear from the table in the year they left Japan.

\section{Infant survival rates}

Infant survival rates were calculated as the number of surviving animals beyond the first year of life as a proportion of all births using two methods, the first including and the second excluding stillbirths. Only captive-born individuals were included in infant survival rate calculations because they have definite known dates of birth, unlike individuals who come from a wild or unknown origin. All but three individuals born in captivity abroad were brought to Japan after having reached at least one year of age, thus were not included in infant survivorship calculations. The majority of wild-born chimpanzees were also estimated to be older than one year at the time of arrival to Japan $(n=27$ estimated as under one).

\section{Life table}


Life tables can provide age-specific survival, mortality, and fecundity rates of a population. Cohort, or generation, life tables include only individuals born in the same (ideally relatively short) time period, following them through their entire lifespan and thus require a very large sample over a specific period of time. In contrast, synthetic life tables incorporate data from all available study years. The synthetic life table presented in this paper was produced in Excel following standard methods used in prior studies (Hill et al. 2001, Muller and Wrangham 2014, Wood et al. 2017), utilizing data exported from the population management software PopLink v2.4. The number of deaths in an interval were divided by the number of individuals existing in that interval to calculate the probability of death at age $\mathrm{x}\left(\mathrm{q}_{\mathrm{x}}\right)$ and the probability of survival $\left(\mathrm{l}_{\mathrm{x}}\right)$ was calculated by multiplying all yearly survival rates $\left(1-\mathrm{q}_{\mathrm{x}}\right)$ from age $\mathrm{x}$ to age $\mathrm{x}-1$. Life expectancy at age $x\left(e_{x}\right)$ was calculated by summing survival probabilities from $1_{x+1}$ to the last year in the life table, $1_{\mathrm{n}}$, and dividing by $1_{\mathrm{x}}$ (then adding a half year due to the assumption that, on average, individuals live six months in the year they die). The life table contains historical event information on every known individual in the population, utilizing their estimated or certain date of birth, date of entry into the population, exit out of the population, and/or death (Faust et al. 2012b). Individuals were thus added to the table either in the year of birth or immigration (here, importation) and removed from the table in the year of death or emigration (exportation or LTF) out of the Japanese population. Those still alive on March 11, 2019 were considered closed. Individuals with an unknown birth date estimate or those deceased with an unknown death date were not included in the life table due to the inability of calculating age (Faust et al. 2012b). Individuals born alive and surviving to at least one day of age or living in Japan during any period ranging January 1, 1921 to March 11, 2019 were included in the life table, resulting in 821 (479 females, 342 males) chimpanzees of 1017 for whom sufficient data existed. Birth and death estimates existed for ten individuals of unknown sex, but they were not included in the life table.

\section{Death seasonality}

To investigate death seasonality, the number of individuals who died in each month across all years was counted using the population management software PMx (http://www.vorte x10.org/PMx.aspx) with data imported from PopLink.

\section{Results}

Of the 1017 individual chimpanzees documented in the GAIN database, just over half ( $n$ $=537,53 \%)$ were recorded as deceased and nearly one-fifth $(n=173,17 \%)$ as lost to follow-up (LTF; exported out of Japan), leaving 307 (30\%) chimpanzees who were alive 
in Japan at the time of writing. Females outnumbered males and made up over half of the historical population ( $n=574,56 \%$ and $n=405,40 \%$, respectively), and 38 (4\%) individuals were of unknown or undecided sex. The majority of individuals were born in captivity ( $n=535,53 \%$ ), almost one-third in Africa ("wild born"; $n=302,30 \%$ ) and many originated from an unknown birthplace $(n=180,18 \%)$. Individuals with a wild or unknown origin were provided an estimated year of birth and thus their age at death or current age is not precise as it is for those born in captivity (median age at import: 2.0 years; average: 2.5 years; range, 1 month-19.24 years; SD 1.9 years). The number of wild-born individuals living in Japan peaked in 1984 at 170. Since 1992, captive-born chimpanzees have outnumbered those born in the wild.

\section{Current age-sex composition}

Age-sex charts illustrate the demographic composition of a population at a given time. Due to the long history of holding chimpanzees in Japan, a bias towards the existence of more young individuals than old did not exist. The current demographic composition showed the opposite pattern, that of an aging population, however with only 23 individuals alive between 30 and 34 years of age compared to 58 chimpanzees between 25 and 29 years and 45 between 35 and 39 years (Fig. 2). Two of every five (40\%) chimpanzees alive in Japan were 33 years of age or older (may be considered "elderly") and over half (63\%) were above 25 years old.

\section{Infant survivorship}

Of the 535 individuals born in captivity, 502 were born in Japan. The birth of the first chimpanzee in Japan was on July 22, 1940 at the Osaka Tennoji Zoo, but the infant was stillborn. Of all captive births in Japan, nearly one in every six $(n=72,14 \%)$ infants were delivered stillborn ("non-live" birth). The number of stillbirths has irregularly increased over the decades, from $13 \%(n=7)$ of all births in the 1970 s, to $10 \%(n=10), 16 \%(n=27)$ and $15 \%(n=16)$ in the following decades, and most recently $20 \%(n=11)$ from 2010 to March 2019. The remaining 430 infants ( $86 \%$ of total births) were born alive ("live" birth) and 421 lived beyond one day of birth. Four-fifths of all chimpanzees born in Japan survived past one week of age $(n=402,80 \%)$ and just over two-thirds reached or surpassed their first birthday $(n=341,68 \%$ ) (Table 1). Causes of death for individuals who died on the day or soon after birth include aggression from other individuals, illness, neglect, and accidental injury. In total, 161 chimpanzees died before reaching their first birthday. Excluding non-live births, the number of chimpanzees who died before reaching one year of age decreases to 89 infants. Considering all births in Japan, the first-year 
infant survival rate for chimpanzees was $68 \%$, but including only live births, this increased to $79 \%$. The one-week survival rate also increased when only live births were considered, from 80 to $94 \%$ (Table 1).

\section{Maximum longevity}

The longevity record for chimpanzees in Japan was set on January 15, 2019 when the longest living individual, a wild-born male named Jhonny estimated to be 68 years old, passed away at the Kobe Oji Zoo (brought to Japan in 1952 at estimated age of 2 years, \pm 1 year age estimate). The second oldest individual in GAIN records was Mimie, a wildborn female who passed away at the Tama Zoological Park in 2015. She lived to an estimated age of 59 years, nearly a decade younger than the oldest male (brought to Japan on March 9, 1958 at estimated age of 1.7 years, \pm 1 year age estimate). While ten females reached or surpassed the estimated age of 50 (Table $2 a$ ), only five males did (Table 2b).

\section{Life table}

Despite having lived at different times and in different facilities across Japan, all individual data were combined in a single, synthetic life table to provide an overview of mortality rates in captivity including as many available data as possible, but excluding stillborn individuals (Table 3). The data contain 9334 observation years on females including 243 deaths, whereas about a third less, 6289 years and 161 deaths, exists for males. Females experienced a higher mortality risk (qx) in the first year of life than males, at 22 and 15\%, respectively (Table 3). From infancy to adulthood, females experienced a consistently slightly lower survival probability compared to males, and at age 30 they reached a 43 and $44 \%$ chance of survival from birth, respectively (Fig. 3). When calculated from one year of birth [1x (1y)], females and males experienced nearly the same survival rate until age 29 where males dropped below females, especially from 36 to 43 years (Table 3). Life expectancy at birth including individuals who survived past one day was 26.3 years for females and 30.3 years for males. Including only individuals who reached or surpassed their first birthday, female and male life expectancy increased to 32.4 and 34.7 years, respectively. Kaplan-Meier estimates indicated that female and male survival curves were not statistically different $(\chi 2=0.2114, \mathrm{df}=1, \mathrm{p}=0.6467)$.

\section{Life expectancy over time}

It was not possible to produce yearly abridged life tables from GAIN data due to the small number of births each year, so in order to investigate whether life expectancy changed over time, we compared the median age of individuals who died in a particular year to 
the median age of individuals alive that year (excluding all individuals below one year of age due to high infant mortality). This allowed us to (1) explore whether median life expectancy was increasing over time and (2) verify whether or not potentially increasing lifespans were an artefact of a greater number of old chimpanzees existing. We found that median life expectancy increased over time, especially over the past few decades, however increasing lifespans may be an artefact of a greater number of older chimpanzees existing (Fig. 4). Nearly 20 years ago, the population was made up of individuals aged around 15 and median age at death was around 20 years; today, the median population age is around 25 years and age at death is 34 . The median age of chimpanzees alive each year in Japan is still increasing and has not yet leveled, likely because many were brought to Japan in the 1980 s and have not yet reached their longevity potential.

\section{Death seasonality}

We found a seasonal effect on the chimpanzee death rate. Chimpanzees in Japan were more likely to die in the winter months (Dec-Feb) than in any other defined season ( $n=108$; Chi-square test, $p<0.001$ ). In comparison, 68 individuals died between March and May, 75 between June and August and 62 between September and November (Fig. 5). Data excluding neonatal deaths (defined as death before one year) were analyzed due to the diverse causes leading to newborn deaths, however a similar pattern was observed in data including neonatal deaths.

\section{Discussion}

In this study, we present a life table featuring data that span nearly a century and include 821 captive chimpanzees who have either previously lived or currently reside in Japan. We wish to make these data available for future comparative investigations into animal life history patterns. To do this, we utilized the Great Ape Information Network (GAIN), an openly accessible database containing the life history information of all apes in Japan. The robust life table and longevity and mortality statistics presented here will hopefully contribute to and broaden our understanding of captive chimpanzee demographic life history patterns.

A low survival period the year following birth is observed across many animal species (Kohler et al. 2006). Courtenay and Santow (1989) reported that $63 \%$ of live-born infants in the Taronga Zoo population survived the first year of life, but this was later lowered to $60 \%$ (Littleton 2005). Dyke et al. (1995) described an 80-86\% survival rate in three major breeding colonies in the United States and a $67 \%$ survival rate for wild infants living 
beyond one year at Gombe. A more recent and expanded dataset collected from five wild chimpanzee populations, including Gombe, revealed that around $80 \%$ of infants survive past one year (Hill et al. 2001). Infants at Kanyawara experience a particularly high survival chance, at $89 \%$ (Muller and Wrangham 2014). Similar to what is observed in combined wild populations as well as in US colonies, $83 \%$ of live-born infants in Japan survived beyond their first birthday, however this rate drops to $68 \%$ when non-live births are included. It is unclear whether all reports from the wild include stillbirths, however this is unlikely as such cases are difficult to observe and thus record.

Almost one in six chimpanzees in Japan are stillborn. Of 391 chimpanzees born from 1980 to 2016 in North American AZA-accredited zoos, 48 (12\%) were stillborn (Saiyed et al. 2018). During the same time period, 63 of 415 (15\%) infants in Japan were stillborn. From 1941 to 2000 at the Taronga Zoo in Australia, seven of 95 (7\%) infants were stillborn and 18 individuals died on the same day of birth (Littleton 2005); in Japan, 45 of $344(13 \%)$ chimpanzees were stillborn. These comparisons expose that chimpanzees experience a higher risk of being stillborn in Japan, however this may be in part due to the inclusion of miscarriages in stillbirth counts, which are not clearly defined in the database. While individuals born alive who did not survive until the second day of life were recorded as "live" birth, a few false stillbirth cases may exist (e.g., labeled "bite wound" or "already dead when found"). Contrary to our expectation that the captive stillbirth rate would decrease as rearing practices improved, it increased over the past decade. Further investigation is required to identify reasons for this.

In Japan, the average life expectancy of a live-born individual at birth is 28.3 years, whereas in the wild a chimpanzee is expected to live less than 15 years (Hill et al. 2001). However, this can depend on the environment of a population; some wild chimpanzees living under highly favorable conditions have an average life expectancy at birth of 32.8 years, higher than the captive population in Japan (Wood et al. 2017). Wild individuals who survive to adulthood (age 12) are likely to reach 30 years of age (Hill et al. 2001). Once a chimpanzee in Japan has reached their first birthday, she or he is expected to live 33.6 more years, and after reaching adulthood (age 12) they are likely to reach 40.4 years of age, suggesting that a higher proportion of captive chimpanzees in Japan survive to old ages compared to their wild counterparts. Unlike wild populations where male mortality is significantly higher than females', survival curves for each sex in captivity in Japan do not differ significantly (Hill et al. 2001; Wood et al. 2017). For unknown reasons, females in Japan experience higher mortality than males in the first year of life, where only $78 \%$ 
of infants survive compared to $85 \%$ of males. At Taronga Zoo, $87 \%$ of females and $67 \%$ of males survived to one year; after this high-risk period, mortality levels were similar until adolescence, when males again experienced a higher risk (Littleton 2005). Environment may shape mortality as much or more than phylogeny, so longevity differences are expected to be found across populations of same-species animals (Bronikowski et al. 2011). This appears to be the case for wild and captive chimpanzees.

The oldest chimpanzees living in wild populations are most commonly female and in their early 50s (Bronikowski et al. 2011; Matsuzawa et al. 2011; Matsuzawa 2018). The oldest individual reported living in the wild is from the Ngogo community in Uganda, estimated to be 66 years old and one of five females above 60 (Wood et al. 2017). In AZA-accredited institutions in the US, data current to 2012 include the oldest chimpanzee ever documented, a wild-born female with an estimated life span of 74 years ( \pm 4 year) at that time (Chimpanzee Species Survival Plan 2012). The oldest chimpanzee in the captive European population is a female estimated to have lived 60 years (Carlsen and de Jongh 2014). Unlike these captive and wild longevity records, the oldest individual in Japan was a male, estimated to be 68 years old ( \pm 1 year). He is among one of the oldest documented chimpanzees in the world. The oldest female in Japan lived 59 years ( \pm 1 year), nearly one decade less. While only five males in Japan surpassed or currently live past the age of 50, ten females do, suggesting that females reach older ages more frequently than males. This reflects maximum longevity patterns in the wild where the majority of old individuals are female.

To our knowledge, only one study has reported on whether wild chimpanzees experience different rates of mortality across seasons, but none have investigated this among captive living individuals. In the wild, a seasonal mortality pattern was not detected for the Gombe chimpanzee community as it was for other primate species, and periods of food scarcity did not significantly influence their death rate (Gogarten et al. 2012). In Japan, chimpanzees are more likely to pass away in one of the winter months (Dec-Feb) than during any other season. Although the causes of heightened mortality during the winter season in Japan are unknown, it may be related to the constant cold temperatures which chimpanzees are not well adapted to. In captivity, food availability remains stable throughout the seasons and although indoor sleeping rooms are typically temperature controlled, it is not possible to carefully control outdoor conditions where most chimpanzees spend their day. Chimpanzees that are contained or choose to remain indoors might experience a heightened risk of injury, disease transmission and/or infection from 
humans. Other animals, including humans and dairy cows, also show an increased risk of mortality during periods of cold weather (Analitis et al. 2008; Cox et al. 2016).

The accuracy of infant survival rates, maximum longevity, and life expectancy calculations depends partly on how long a captive population exists, therefore results are expected to vary over time. At establishment, a colony is not typically made up of individuals belonging to diverse age classes, but usually contains a majority of young animals. Thus, the presence of older individuals in a group is most likely a function of the age of the colony or institution where they are held (Dyke et al. 1995). Captive chimpanzees around the world are only recently developing into aging populations and so current life expectancy calculations are likely underestimated, until a larger number of individuals reach into old age and more data accrue (Faust et al. 2012b). Improved management and veterinarian practices over time may also influence these calculations. While we are able to show that the median age at death of chimpanzees in Japan is increasing year after year, we also illustrate how the age of individuals alive each year is increasing. This is necessary to take into consideration because chimpanzees in captivity have not yet reached their full aging potential; many were brought to Japan in the 1980's and thus current increasing lifespans may be an artefact of more old individuals existing. Whether or not life expectancy has increased over time due to improving practices in captivity is a difficult question to answer and may require more time to pass before any meaningful conclusion is made (i.e., until the median age of those alive each year no longer increases). It should also be pointed out that due to the inclusion of early data (pre 1980s) in this study, a time when little was known about how to care for chimpanzees in captivity, life expectancy predictions for individuals living in Japan are likely to be underestimated.

Studbook and other historical databases are excellent resources for the study of animal biology, care and management (Fisken et al. 2018). Studbook data from accredited American zoos have previously been used to investigate chimpanzee birth timing (Wagner and Ross 2008) and great ape stillbirth rates (Saiyed et al. 2018), and from European zoos to understand chimpanzee geographic origins and admixture (Hvilsom et al. 2013). Few other databases exist such as AnAge (de Magalhães and Costa 2009), PanTHE-RIA (Jones et al. 2009) and All The World's Primates (Rowe and Myers 2017), but captive data are still most commonly maintained in difficult-to-access national or regional studbooks. The Great Ape Information Network is unique in that available individual life history data on five ape species (all except humans) in Japan is recorded 
on a near daily basis and is openly accessible to interested researchers and the public. Another unique point of the database is that euthanasia is not practiced in Japan, resulting in life history data unaffected by artificial death (Hayashi et al. 2013; Matsuzawa 2016a). Future studies utilizing GAIN data will apply mortality estimates to investigate the relationship between longevity and reproductive parameters including age at first birth, inter-birth interval and number of offspring, and also between longevity and individual history of biomedical experimentation. As populations of chimpanzees and other longlived animals in captivity around the world are steadily aging, it seems an appropriate time to analyze, or re-analyze, collated data in order to obtain a more complete understanding of their life history patterns.

Acknowledgements The authors would like to thank the AZA Population Management and Chicago Zoological Society staff for assistancewith questions regarding PopLink and PMx, and the two anonymousreviewers who provided crucial feedback on the original manuscript.Research was supported by SGU MEXT to K.H. and MEXT-JSPSGrants (\#16H06283 to T. M., 15H05709 to M. T. and 18H05524 to S. H.); LGP-U04, Core-toCore Program CCSN and the Great ApeInformation Network (GAIN) to T.M.

\section{References}

Analitis A, Katsouyanni K, Biggeri A, Baccini M, Forsberg B, Bisanti L, Kirchmayer U, Ballester F, Cadum E, Goodman PG, Hojs A (2008) Effects of cold weather on mortality: results from 15 European cities within the PHEWE project. Am J Epidemiol 168:1397-1408

Ballou JD, Lacy RC, Pollak JP (2010) PMx: software for demographic and genetic analysis and management of pedigreed populations. Chicago Zoological Society, Brookfield

Bronikowski AM, Altmann J, Brockman DK, Cords M, Fedigan LM, Pusey A, Stoinski T, Morris WF, Strier KB, Alberts SC (2011) Aging in the natural world: comparative data reveal similar mortality patterns across primates. Science 331:1325-1328

Carlsen F, de Jongh T (2014) European studbook for the chimpanzee (Pan troglodytes). Copenhagen Zoo, Frederiksberg

Chimpanzee Species Survival Plan (2012) 2012 North Americanregional chimpanzee studbook (Pan troglodytes). Lincoln Park Zoo, Chicago

Courtenay J, Santow G (1989) Mortality of wild and captive chimpanzees. Folia Primatol 


\section{$52: 167-177$}

Cox B, Gasparrini A, Catry B, Delcloo A, Bijnens E, Vangronsveld J,Nawrot TS (2016) Mortality related to cold and heat. What do welearn from dairy cattle? Environ Res 149:231-238

de Magalhães JP, Costa J (2009) A database of vertebrate longevity records and their relation to other life-history traits. J Evol Biol 22:1770-1774

Dyke B, Gage TB, Alford PL, Swenson B, Williams-Blangero S (1995) Model life table for captive chimpanzees. Am J Primatol 37:25-37

Faust LJ, Bergstrom YM, Thompson SD, Bier L (2012a) PopLink version 2.4. Lincoln Park Zoo, Chicago

Faust LJ, Bier L, Schowe K, Gazlay T (2012b) PopLink 2.4: user'smanual. Lincoln Park Zoo, Chicago

Fisken FA, Carlsen F, Elder M, de Jongh T, Pereboom JJM, Pohl B,Rietkerk F, Ross SR, Taniguchi A (2018) Global populationrecords and managed-programme updates for the great apes. IntZoo Yearb 52:212-226

Gogarten JF, Brown LM, Chapman CA, Cords M, Doran-Sheehy D,Fedigan LM, Grine FE, Perry S, Pusey E, Sterck EH, Wich SA(2012) Seasonal mortality patterns in nonhuman primates: implications for variation in selection pressures across environments.Evolution 66:3252-3266

Hayashi M, Sakuraba Y, Watanabe S, Kaneko A, Matsuzawa T (2013)Behavioral recovery from tetraparesis in a captive chimpanzee.Primates 54:237-243

Hill K, Boesch C, Goodall J, Pusey A, Williams J, Wrangham R (2001)Mortality rates among wild chimpanzees. J Hum Evol 40:437-450

Hirata S, Morimura N, Watanuki K, Ross SR (in press) The establishment of sanctuaries for former laboratory chimpanzees: challenges, successes, and cross-cultural context. In: Hopper L, RossSR (eds) Chimpanzees in context. The University of Chicago Press, Chicago

Hvilsom C, Frandsen P, Børsting C, Carlsen F, Sallé B, Simonsen BT,Siegismund HR (2013) Understanding geographic origins andhistory of admixture among chimpanzees in European zoos, withimplications for future breeding programmes. Heredity 110:586

Jones KE, Bielby J, Cardillo M, Fritz SA, O’Dell J, Orme CDL, Safi K,Sechrest W, Boakes EH, Carbone C, Connolly C (2009) PanTHE-RIA: a species-level database of life history, ecology, and geography of extant and recently extinct mammals. Ecology 90:2648

Kaplan H, Hill K, Lancaster J, Hurtado AM (2000) A theory of human life history 
evolution: diet, intelligence, and longevity. Evol Anthropol 9:156-185

Kohler IV, Preston SH, Lackey LB (2006) Comparative mortalitylevels among selected species of captive animals. Demogr Res 15:413-434

Littleton J (2005) Fifty years of chimpanzee demography at TarongaPark Zoo. Am J Primatol 67:281-298

Matsuzawa T (2016a) Euthanasia is not an option: 10 years' care of achimpanzee with acute tetraparesis. Primates 57:291-293Matsuzawa T (2016b) SAGA and GAIN for great apes. Primates 57:1-2 Matsuzawa T (2018) Chimpanzee Velu: the wild chimpanzee who passed away at the estimated age of 58. Primates 59:107-111

Matsuzawa T, Humle T, Sugiyama Y (2011) The chimpanzees of Bossou and Nimba. Springer, New York

Morimura N, Idani GI, Matsuzawa T (2011) The first chimpanzee sanctuary in Japan: an attempt to care for the "surplus" of biomedicalresearch. Am J Primatol 73:226-232

Muller MN, Wrangham RW (2014) Mortality rates among Kanyawarachimpanzees. J Hum Evol 66:107-114

Ochiai T, Watanuki K, Udono T, Morimura N, Hirata S, Tomonaga M, Idani G, Matsuzawa T (2015) The history of captive chimpanzees (Pan troglodytes) in Japan 1920-1950. Primate Res 31:19-29 (in Japanese with English summary)

Rowe N, Myers M (2017) All The World's Primates. Int Encycl Primatol. https://doi.org/10.1002/9781119179313

Saiyed ST, Liubicich RC, Fidino M, Ross SR (2018) Stillbirth ratesacross three ape species in accredited American zoos. Am J Primatol 80:e22870. https://doi.org/10.1002/ajp.22870

Thompson ME, Jones JH, Pusey AE, Brewer-Marsden S, Goodall J,Marsden D, Matsuzawa T, Nishida T, Reynolds V, Sugiyama Y,Wrangham RW (2007) Aging and fertility patterns in wild chimpanzees provide insights into the evolution of menopause. CurrBiol 17:2150-2156

Tidière M, Gaillard JM, Berger V, Müller DW, Lackey LB, GimenezO, Clauss M, Lemaitre JF (2016) Comparative analyses of longevity and senescence reveal variable survival benefits of living inzoos across mammals. Sci Rep 6:36361. https://doi.org/10.1038/ srep36361

Wagner KE, Ross SR (2008) Chimpanzee (Pan troglodytes) birth patterns and human presence in zoological settings. Am J Primatol 70:703-706

Watanuki K, Ochiai T, Hirata S, Morimura N, Tomonaga M, Idani G,Matsuzawa T (2014) Review and long-term survey of the status of captive chimpanzees in Japan in 19262013. Primate Res30:147-156 
Wood BM, Watts DP, Mitani JC, Langergraber KE (2017) Favorableecological circumstances promote life expectancy in chimpanzeessimilar to that of human hunter-gatherers. J Hum Evol 105:41-56

\section{Figures}

Fig. 1 A chimpanzee eats a mango while another carefully observes at Kumamoto Sanctuary

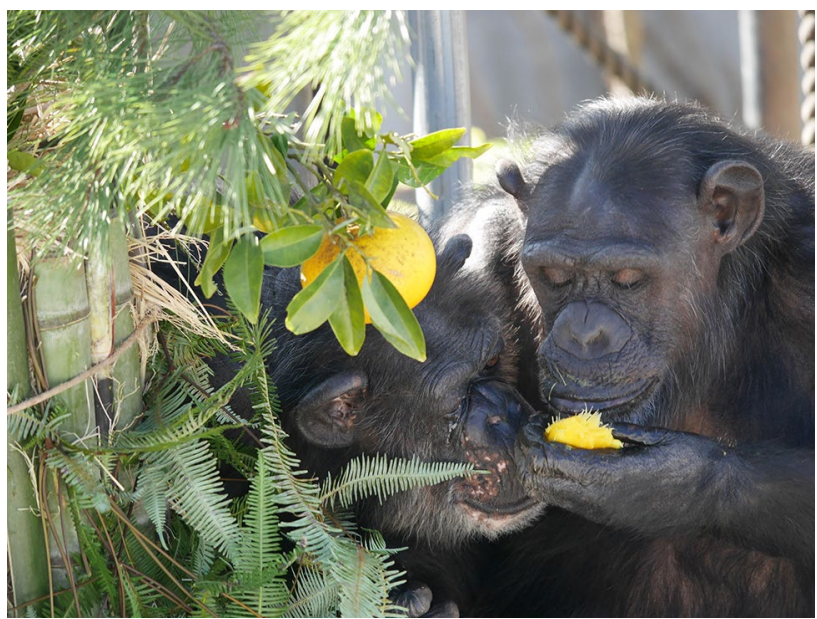


Fig. 2 Current age-sex composition of captive chimpanzees in Japan as of March 11, $2019(n=307)$

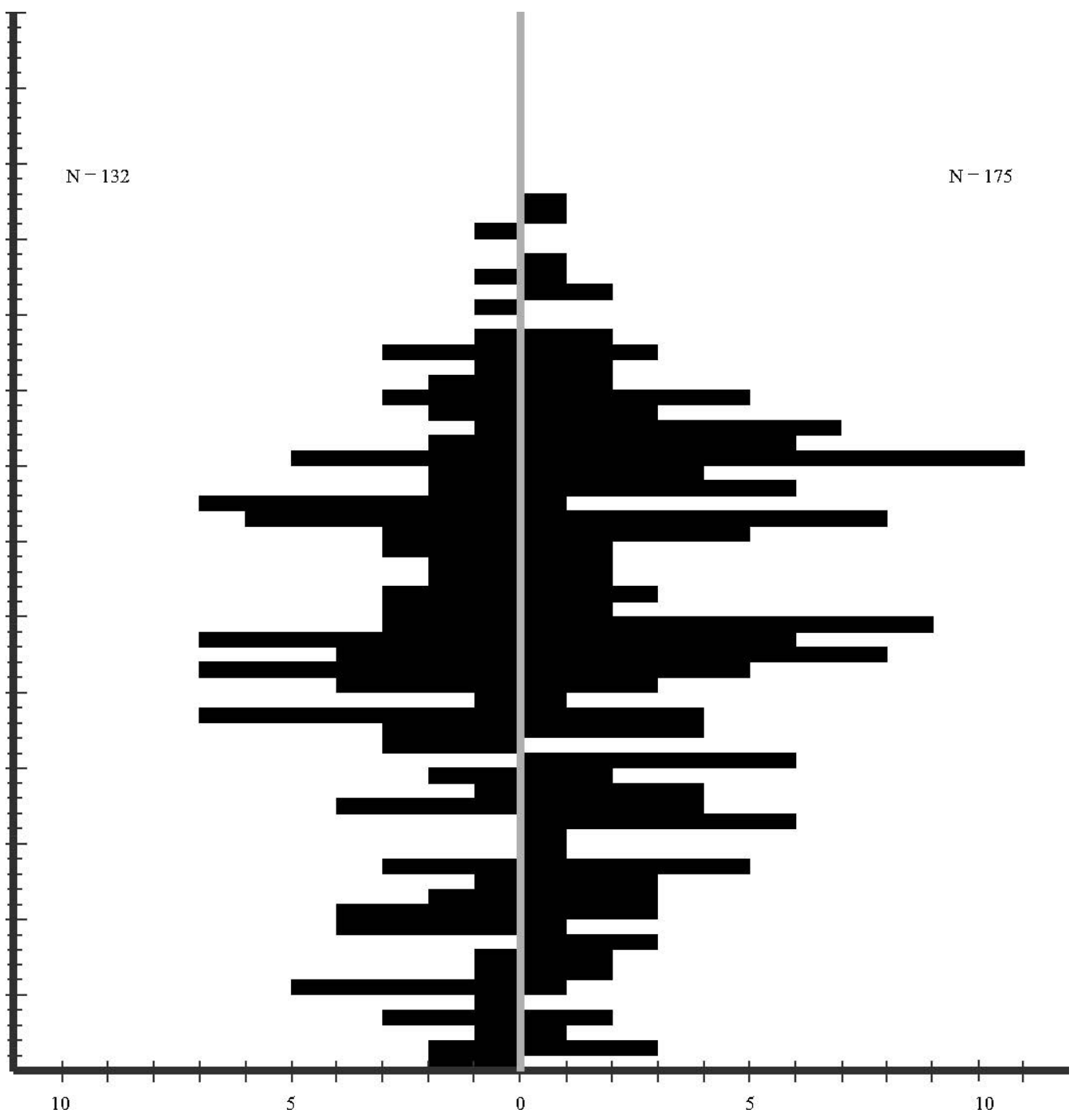

Table 1 Chimpanzee infant survival rates in Japan

\begin{tabular}{llll}
\hline & $\begin{array}{c}n^{\text {Including }} \\
\text { stillbirth (\%) }\end{array}$ & $\begin{array}{l}\text { Including only live- } \\
\text { born (\%) }\end{array}$ \\
\hline Captive births (in Japan) & 502 & & $(n=430)$ \\
Stillborn (non-live birth) & 72 & $14.3 \%$ & - \\
Survival past one week402 & $80.1 \%$ & $93.5 \%$ \\
Survival past one year & 341 & $67.9 \%$ & $79.3 \%$
\end{tabular}


Table 2 Ten oldest female chimpanzees in Japan (a), and ten oldest male chimpanzees in Japan (b)

Gain ID Status Origin Estimated age at import (degree oferror) Age

(a) Ten oldest female chimpanzees in Japan

$\begin{array}{lllll}7 & \text { Dead } & \text { Wild born } & 1.7 \text { years }( \pm 1) & 59.1 \\ 11 & \text { Living } & \text { Unknown } & 2.0 \text { years }( \pm 1) & 57.6 \\ 15 & \text { Living } & \text { Unknown } & 1 \text { month }(+1) & 56.9 \\ 2 & \text { Dead } & \text { Wild born } & 1.9 \text { years }( \pm 1) & 53.5 \\ 26 & \text { Living } & \text { Wild born } & 1.4 \text { years }( \pm 1) & 53.6 \\ 42 & \text { Living } & \text { Unknown } & 4.1 \text { years }( \pm 1) & 52.6 \\ 29 & \text { Living } & \text { Captive born } & \text { n/a } & 51.6 \\ 81 & \text { Living } & \text { Unknown } & 7.9 \text { years }( \pm 6 \text { month }) & 51.6 \\ 13 & \text { Dead } & \text { Captive born } & \text { n/a } & 51.1 \\ 436 & \text { Dead } & \text { Wild born } & 2.0 \text { years }( \pm 2) & 50.9\end{array}$

(b) Ten oldest male chimpanzees in Japan

\begin{tabular}{lllll}
3 & Dead & Wild born & 2.0 years $( \pm 2)$ & 68.5 \\
20 & Living & Wild born & 1.0 years $( \pm 1)$ & 55.6 \\
437 & Living & Wild born & 2.0 years $( \pm 2)$ & 52.6 \\
31 & Dead & Unknown & 1.7 years $( \pm 1)$ & 50.5 \\
33 & Living & Captive born & n/a & 50.4 \\
132 & Living & Wild born & 6.3 years $( \pm 1)$ & 48.6 \\
1 & Dead & Wild born & 6.9 years $( \pm 1)$ & 48.1 \\
126 & Living & Unknown & 2 years $( \pm 2)$ & 47.6 \\
110 & Living & Wild born & 4.7 years $( \pm 1)$ & 47.6 \\
72 & Living & Wild born & 1.5 years $( \pm 1$ month) & 46.9 \\
\hline 7 & Dead & Wild born & 1.7 years $( \pm 1)$ & 59.1 \\
11 & Living & Unknown & 2.0 years $( \pm 1)$ & 57.6 \\
15 & Living & Unknown & 1 month $(+1)$ & 56.9 \\
2 & Dead & Wild born & 1.9 years $( \pm 1)$ & 53.5 \\
26 & Living & Wild born & 1.4 years $( \pm 1)$ & 53.6 \\
42 & Living & Unknown & 4.1 years $( \pm 1)$ & 52.6 \\
29 & Living & Captive born & n/a & 51.6
\end{tabular}


Table 3 Life table by single year of age and sex for captive chimpanzees in Japan spanning 1921 to February $2019(\mathrm{n}=821)$

Age Females

$n_{x} \quad d x \quad q$ lx $\quad l_{x} \quad l_{x}$

(0y) (1y) (5y)
Males lx $\quad l_{x} \quad l_{x}$

$(0 \mathrm{y}) \quad(1 \mathrm{y}) \quad(5 \mathrm{y})$

\begin{tabular}{|c|c|c|c|c|c|c|c|c|c|c|c|c|c|c|}
\hline 0 & 222 & 48 & 0.22 & 1.00 & & & 26.3 & 194 & 30 & 0.15 & & & & 30.3 \\
\hline 1 & 212 & 5 & 0.02 & 0.78 & 1.00 & & 32.4 & 181 & 3 & 0.02 & 0.85 & 1.00 & & 34.7 \\
\hline 2 & 289 & 6 & 0.02 & 0.77 & 0.98 & & 32.2 & 223 & 5 & 0.02 & 0.83 & 0.98 & & 34.3 \\
\hline 3 & 334 & 5 & 0.01 & 0.75 & 0.96 & & 31.8 & 248 & 4 & 0.02 & 0.81 & 0.96 & & 34.1 \\
\hline 4 & 352 & 5 & 0.01 & 0.74 & 0.94 & & 31.3 & 251 & 5 & 0.02 & 0.80 & 0.95 & & 33.6 \\
\hline 5 & 363 & 2 & 0.01 & 0.73 & 0.93 & 1.00 & 30.8 & 256 & 1 & 0.00 & 0.78 & 0.93 & 1.00 & 33.3 \\
\hline 6 & 364 & 3 & 0.01 & 0.72 & 0.92 & 0.99 & 29.9 & 251 & 3 & 0.01 & 0.78 & 0.92 & 1.00 & 32.4 \\
\hline 7 & 364 & 8 & 0.02 & 0.72 & 0.92 & 0.99 & 29.2 & 248 & 2 & 0.01 & 0.77 & 0.91 & 0.98 & 31.8 \\
\hline 8 & 355 & 6 & 0.02 & 0.70 & 0.90 & 0.96 & 28.8 & 245 & 6 & 0.02 & 0.77 & 0.91 & 0.98 & 31.1 \\
\hline 9 & 347 & 5 & 0.01 & 0.69 & 0.88 & 0.95 & 28.3 & 239 & 4 & 0.02 & 0.75 & 0.88 & 0.95 & 30.8 \\
\hline 10 & 338 & 8 & 0.02 & 0.68 & 0.87 & 0.93 & 27.7 & 230 & 4 & 0.02 & 0.73 & 0.87 & 0.94 & 30.3 \\
\hline 11 & 325 & 10 & 0.03 & 0.66 & 0.85 & 0.91 & 27.4 & 219 & 5 & 0.02 & 0.72 & 0.85 & 0.92 & 29.9 \\
\hline 12 & 310 & 9 & 0.03 & 0.64 & 0.82 & 0.88 & 27.2 & 209 & 10 & 0.05 & 0.70 & 0.83 & 0.90 & 29.5 \\
\hline 13 & 297 & 3 & 0.01 & 0.62 & 0.80 & 0.86 & 27.0 & 199 & 4 & 0.02 & 0.67 & 0.79 & 0.86 & 30.0 \\
\hline 14 & 288 & 7 & 0.02 & 0.62 & 0.79 & 0.85 & 26.3 & 186 & 1 & 0.01 & 0.66 & 0.78 & 0.84 & 29.6 \\
\hline 15 & 276 & 3 & 0.01 & 0.60 & 0.77 & 0.83 & 25.9 & 187 & 1 & 0.01 & 0.65 & 0.77 & 0.83 & 28.8 \\
\hline 16 & 271 & 7 & 0.03 & 0.60 & 0.76 & 0.82 & 25.2 & 183 & 1 & 0.01 & 0.65 & 0.77 & 0.83 & 27.9 \\
\hline 17 & 258 & 5 & 0.02 & 0.58 & 0.74 & 0.80 & 24.9 & 181 & 1 & 0.01 & 0.65 & 0.77 & 0.83 & 27.1 \\
\hline 18 & 245 & 2 & 0.01 & 0.57 & 0.73 & 0.78 & 24.3 & 176 & 7 & 0.04 & 0.64 & 0.76 & 0.82 & 26.2 \\
\hline 19 & 237 & 3 & 0.01 & 0.57 & 0.72 & 0.78 & 23.5 & 167 & 6 & 0.04 & 0.62 & 0.73 & 0.79 & 26.3 \\
\hline 20 & 232 & 8 & 0.03 & 0.56 & 0.71 & 0.77 & 22.8 & 159 & 4 & 0.03 & 0.60 & 0.70 & 0.76 & 20.2 \\
\hline 21 & 217 & 3 & 0.01 & 0.54 & 0.69 & 0.74 & 22.6 & 153 & 0 & 0.00 & 0.58 & 0.69 & 0.74 & 25. \\
\hline 22 & 212 & 3 & 0.01 & 0.53 & 0.68 & 0.73 & 21.9 & 151 & 3 & 0.02 & 0.58 & 0.69 & 0.74 & 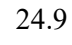 \\
\hline 23 & 206 & 9 & 0.04 & 0.52 & 0.67 & 0.72 & 21.3 & 144 & 5 & 0.03 & 0.57 & 0.67 & 0.73 & 24. \\
\hline 24 & 191 & 5 & 0.03 & 0.50 & 0.64 & 0.69 & 21.2 & 132 & 8 & 0.06 & 0.55 & 0.65 & 0.70 & 24 \\
\hline 25 & 183 & 3 & 0.02 & 0.49 & 0.62 & 0.67 & 20.8 & 122 & 3 & 0.02 & 0.52 & 0.61 & 0.66 & 24. \\
\hline 26 & 176 & 4 & 0.02 & 0.48 & 0.61 & 0.66 & 20.1 & 115 & 2 & 0.02 & 0.50 & 0.60 & 0.64 & \\
\hline 27 & 165 & 7 & 0.04 & 0.47 & 0.60 & 0.64 & 19.5 & 107 & 7 & 0.07 & 0.49 & 0.58 & 0.63 & \\
\hline & 152 & 3 & 0.02 & 0.45 & 0.57 & 0.62 & 19.4 & 92 & 4 & 0.04 & 0.46 & 0.55 & 0.59 & \\
\hline
\end{tabular}




\begin{tabular}{|c|c|c|c|c|c|c|c|c|c|c|c|c|c|c|}
\hline 29 & 142 & 3 & 0.02 & 0.44 & 0.56 & 0.61 & 18.8 & 81 & 0 & 0.00 & 0.44 & 0.52 & 0.56 & 24.6 \\
\hline 30 & 129 & 3 & 0.02 & 0.43 & 0.55 & 0.59 & 18.2 & 78 & 0 & 0.00 & 0.44 & 0.52 & 0.56 & 23.6 \\
\hline 31 & 123 & 3 & 0.02 & 0.42 & 0.54 & 0.58 & 17.6 & 75 & 2 & 0.03 & 0.44 & 0.52 & 0.56 & 22.6 \\
\hline 32 & 117 & 4 & 0.03 & 0.41 & 0.52 & 0.56 & 17.0 & 70 & 1 & 0.01 & 0.43 & 0.51 & 0.55 & 22.2 \\
\hline 33 & 111 & 0 & 0.00 & 0.40 & 0.51 & 0.55 & 16.6 & 67 & 0 & 0.00 & 0.42 & 0.50 & 0.54 & 21.5 \\
\hline 34 & 109 & 3 & 0.03 & 0.40 & 0.51 & 0.55 & 15.6 & 65 & 3 & 0.05 & 0.42 & 0.50 & 0.54 & 20.5 \\
\hline 35 & 104 & 0 & 0.00 & 0.39 & 0.49 & 0.53 & 15.0 & 60 & 4 & 0.07 & 0.40 & 0.48 & 0.52 & 20.4 \\
\hline 36 & 100 & 3 & 0.03 & 0.39 & 0.49 & 0.53 & 14.0 & 52 & 0 & 0.00 & 0.38 & 0.45 & 0.48 & 20.9 \\
\hline 37 & 90 & 4 & 0.04 & 0.37 & 0.48 & 0.51 & 13.4 & 46 & 3 & 0.07 & 0.38 & 0.45 & 0.48 & 19.9 \\
\hline 38 & 83 & 2 & 0.02 & 0.36 & 0.46 & 0.49 & 13.0 & 36 & 4 & 0.11 & 0.35 & 0.42 & 0.45 & 20.2 \\
\hline 39 & 76 & 1 & 0.01 & 0.35 & 0.45 & 0.48 & 12.4 & 30 & 0 & 0.00 & 0.31 & 0.37 & 0.40 & 21.7 \\
\hline 40 & 70 & 5 & 0.07 & 0.34 & 0.44 & 0.47 & 11.5 & 28 & 0 & 0.00 & 0.31 & 0.37 & 0.40 & 20.7 \\
\hline 41 & 54 & 2 & 0.04 & 0.32 & 0.41 & 0.44 & 11.4 & 23 & 1 & 0.04 & 0.31 & 0.37 & 0.40 & 19.7 \\
\hline 42 & 46 & 3 & 0.07 & 0.31 & 0.39 & 0.42 & 10.8 & 20 & 1 & 0.05 & 0.30 & 0.35 & 0.38 & 19.6 \\
\hline 43 & 36 & 2 & 0.06 & 0.29 & 0.37 & 0.40 & 10.5 & 18 & 0 & 0.00 & 0.29 & 0.34 & 0.36 & 19.6 \\
\hline 44 & 31 & 1 & 0.03 & 0.27 & 0.35 & 0.37 & 10.1 & 16 & 0 & 0.00 & 0.29 & 0.34 & 0.36 & 18.6 \\
\hline 45 & 24 & 1 & 0.04 & 0.26 & 0.34 & 0.36 & 9.4 & 13 & 0 & 0.00 & 0.29 & 0.34 & 0.36 & 17.6 \\
\hline 46 & 21 & 1 & 0.05 & 0.25 & 0.32 & 0.35 & 8.8 & 11 & 0 & 0.00 & 0.29 & 0.34 & 0.36 & 16.6 \\
\hline 47 & 18 & 2 & 0.11 & 0.24 & 0.31 & 0.33 & 8.2 & 10 & 0 & 0.00 & 0.29 & 0.34 & 0.36 & 15.6 \\
\hline 48 & 14 & 0 & 0.00 & 0.21 & 0.27 & 0.29 & 8.2 & 7 & 1 & 0.14 & 0.29 & 0.34 & 0.36 & 14.6 \\
\hline 49 & 11 & 1 & 0.09 & 0.21 & 0.27 & 0.29 & 7.2 & 5 & 0 & 0.00 & 0.24 & 0.29 & 0.31 & 15.9 \\
\hline 50 & 10 & 1 & 0.10 & 0.19 & 0.25 & 0.27 & 6.8 & 5 & 1 & 0.20 & 0.24 & 0.29 & 0.31 & 14.9 \\
\hline 51 & 9 & 1 & 0.11 & 0.17 & 0.22 & 0.24 & 6.5 & 3 & 0 & 0.00 & 0.20 & 0.23 & 0.25 & 17.5 \\
\hline 52 & 6 & 0 & 0.00 & 0.16 & 0.20 & 0.21 & 6.3 & 3 & 0 & 0.00 & 0.20 & 0.23 & 0.25 & 16.5 \\
\hline 53 & 5 & 1 & 0.20 & 0.16 & 0.20 & 0.21 & 5.3 & 2 & 0 & 0.00 & 0.20 & 0.23 & 0.25 & 15.5 \\
\hline 54 & 3 & 0 & 0.00 & 0.12 & 0.16 & 0.17 & 5.5 & 2 & 0 & 0.00 & 0.20 & 0.23 & 0.25 & 14.5 \\
\hline 55 & 3 & 0 & 0.00 & 0.12 & 0.16 & 0.17 & 4.5 & 2 & 0 & 0.00 & 0.20 & 0.23 & 0.25 & 13.5 \\
\hline 56 & 3 & 0 & 0.00 & 0.12 & 0.16 & 0.17 & 3.5 & 1 & 0 & 0.00 & 0.20 & 0.23 & 0.25 & 12.5 \\
\hline 57 & 3 & 0 & 0.00 & 0.12 & 0.16 & 0.17 & 2.5 & 1 & 0 & 0.00 & 0.20 & 0.23 & 0.25 & 11.5 \\
\hline 58 & 1 & 0 & 0.00 & 0.12 & 0.16 & 0.17 & 1.5 & 1 & 0 & 0.00 & 0.20 & 0.23 & 0.25 & 10.5 \\
\hline 59 & 1 & 1 & 1.00 & 0.12 & 0.16 & 0.17 & 0.5 & 1 & 0 & 0.00 & 0.20 & 0.23 & 0.25 & 9.5 \\
\hline 60 & & & & & & & & 1 & 0 & 0.00 & 0.20 & 0.23 & 0.25 & 8.5 \\
\hline 61 & & & & & & & & 1 & 0 & 0.00 & 0.20 & 0.23 & 0.25 & 7.5 \\
\hline 62 & & & & & & & & 1 & 0 & 0.00 & 0.20 & 0.23 & 0.25 & 6.5 \\
\hline 63 & & & & & & & & 1 & 0 & 0.00 & 0.20 & 0.23 & 0.25 & 5.5 \\
\hline
\end{tabular}




$\begin{array}{llllllll}64 & 1 & 0 & 0.00 & 0.20 & 0.23 & 0.25 & 4.5 \\ 65 & 1 & 0 & 0.00 & 0.20 & 0.23 & 0.25 & 3.5 \\ 66 & 1 & 0 & 0.00 & 0.20 & 0.23 & 0.25 & 2.5 \\ 67 & 1 & 0 & 0.00 & 0.20 & 0.23 & 0.25 & 1.5 \\ 68 & 1 & 1 & 1.00 & 0.20 & 0.23 & 0.25 & 0.5\end{array}$

$n_{x}$ number of individuals at risk, $d_{x}$ number of deaths between age $x$ and $x+1, q_{x}$ probability of deathwithin age interval $(x, x+n), l_{x}(0 \mathrm{y})$ probability of survival from birth to age $x, l_{x}(1 \mathrm{y})$ probability of sur- vival from 1 year to age $x, l_{x}(5 y)$ probability of survival from 5 years to age $x, e_{x}$ remaining life expectancy(years) at age $x$ 
Fig. 3 Age-specific probability of survival from birth $\left(1_{x}\right)$ for captive chimpanzees in Japan $(n=821)$

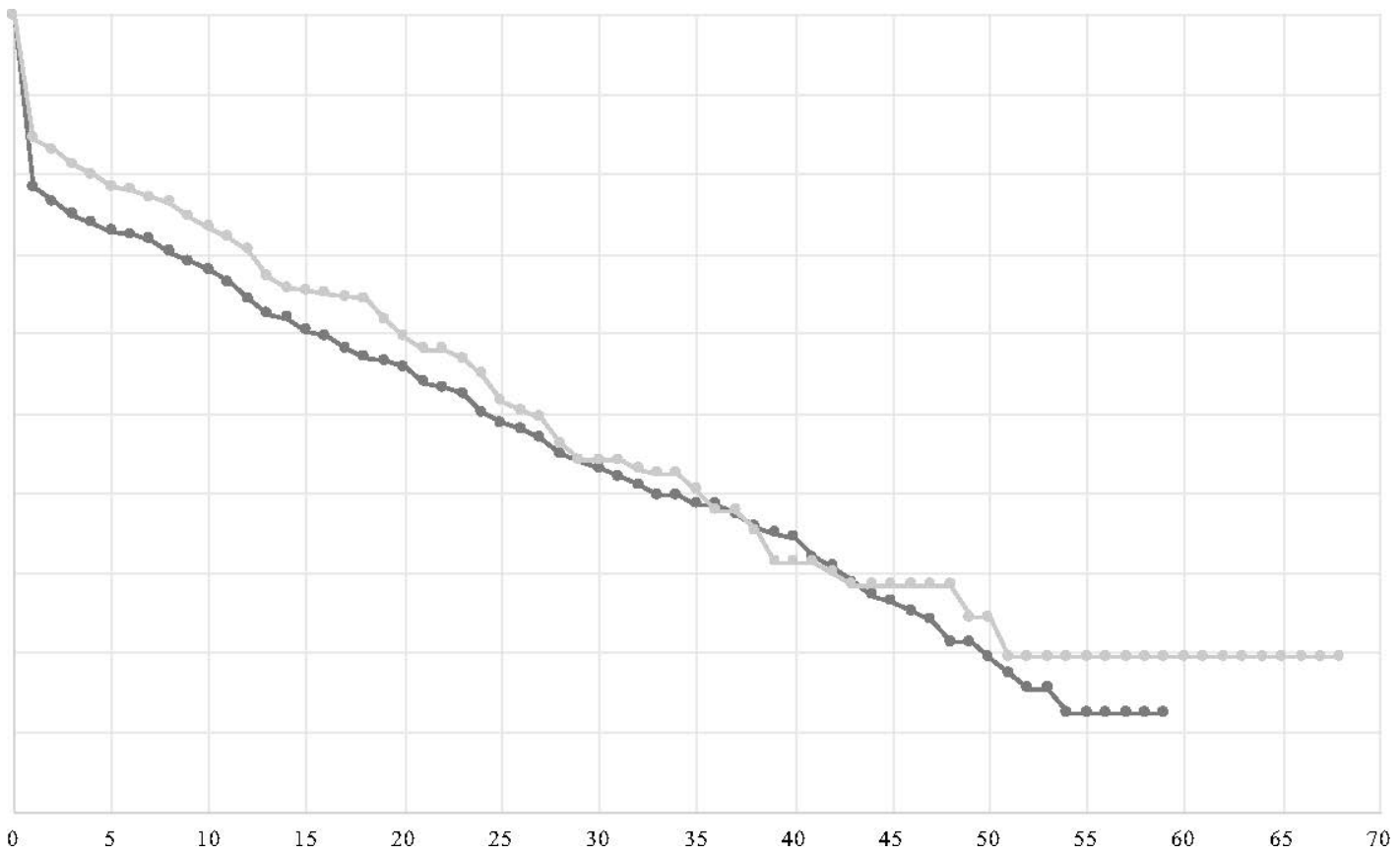

Fig. 4 Moving averages over 10 years of the median age at death and of chimpanzees living each year in Japan

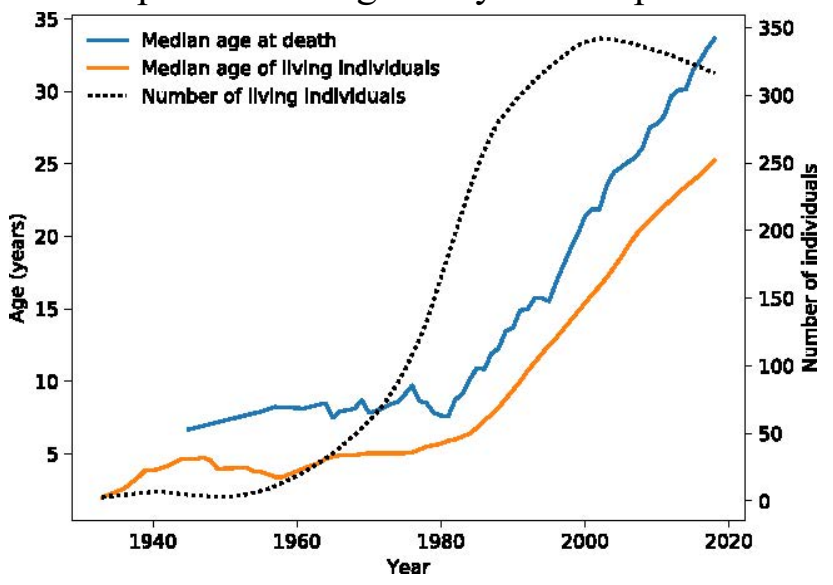


Fig. 5 Chimpanzee death rate by month in Japan (winter = Dec-Feb; spring $=$ Mar-May; summer $=$ Jun - Aug; Fall $=$ Sep-Nov $)$

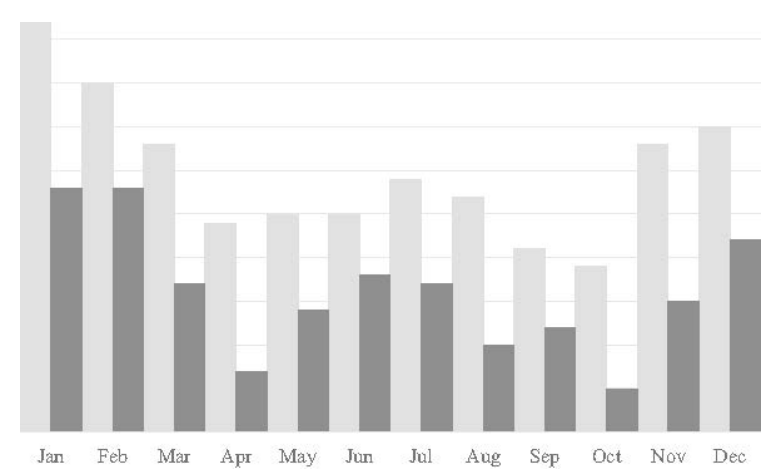

